\title{
Allele Frequency Distribution in PNLIP Promoter SNP Is Different between High-Marbled and Low-Marbled Japanese Black Beef Cattle
}

\author{
Youji Muramatsu' ${ }^{1}$, Hideki Tanomura², Takeshi Ohta ${ }^{3}$, Hiroyuki Kose ${ }^{4}$, Takahisa Yamada ${ }^{*}$ \\ ${ }^{1}$ Department of Nutritional Sciences for Well-Being, Faculty of Health Sciences for Welfare, Kansai University of \\ Welfare Sciences, Osaka, Japan \\ 'Laboratory of Animal Genetics, Graduate School of Science and Technology, Niigata University, Niigata, Japan \\ ${ }^{3}$ Central Pharmaceutical Research Institute, Japan Tobacco, Inc., Osaka, Japan \\ ${ }^{4}$ Department of Life Science, Division of Natural Sciences, International Christian University, Tokyo, Japan \\ Email: "tyamada@agr.niigata-u.ac.jp
}

Received 28 December 2015; accepted 18 April 2016; published 21 April 2016

Copyright (C) 2016 by authors and Scientific Research Publishing Inc.

This work is licensed under the Creative Commons Attribution International License (CC BY).

http://creativecommons.org/licenses/by/4.0/

(c) (i) Open Access

\begin{abstract}
Marbling defined by the amount and distribution of intramuscular fat is regarded as an economically important trait of beef cattle in Japan. The pancreatic lipase gene (PNLIP) is located within the genomic region of a bovine marbling quantitative trait locus. The rat homologue of PNLIP has been previously shown to be regarded as a possible candidate for the gene responsible for intramuscular fat content. These findings suggested that PNLIP was a positional and functional candidate for the marbling gene. In this study, we detected a single nucleotide polymorphism (SNP), g.37288470A > G, at 1917 bp upstream of the PNLIP transcription initiation site between Holstein steers and somatic nuclear-derived cloned steers from a Japanese Black sire with a very high estimated breeding value for marbling by sequencing analysis. Further, we found statistically significant difference in the allelic distribution of the SNP between 17 Japanese Black unrelated sires with extremely high predicted breeding values for marbling and 17 sires with extremely low ones $(P=0.0332)$. Our findings suggest that g.37288470A $>$ G SNP in the promoter region of $P N L I P$ might be associated with marbling by altering its gene expression, and be useful for effective marker-assisted selection to increase the levels of marbling in Japanese Black beef cattle.
\end{abstract}

Keywords

${ }^{*}$ Corresponding author.

How to cite this paper: Muramatsu, Y., Tanomura, H., Ohta, T., Kose, H. and Yamada, T. (2016) Allele Frequency Distribution in PNLIP Promoter SNP Is Different between High-Marbled and Low-Marbled Japanese Black Beef Cattle. Open Journal of Animal Sciences, 6, 137-141. http://dx.doi.org/10.4236/ojas.2016.62017 


\section{Introduction}

Intramuscular fat deposition, so called marbling, is an important factor for evaluation of beef quality. High levels of marbling improve the palatability and acceptability of beef by affecting the taste and tenderness of the meat [1]-[3]. Marbling is the main target of the beef industry in Japan [4], and there is a great interest in the development of more effective marker-assisted cattle breeding scheme for increasing marbling levels.

The pancreatic lipase is involved in the hydrolysis of dietary triglycerides to fatty acids, which is essential for the intestinal absorption of long-chain triglyceride fatty acids [5]. An increase in pancreatic lipase amount or activity should result in excess energy income and then the increase of intramuscular fat content. It was previously reported that the bovine pancreatic lipase gene $(P N L I P)$ was located within the genomic region of a quantitative trait locus for marbling on bovine chromosome 26 [6]. Further, we showed that the rat homologue of PNLIP was regarded as a possible candidate for the gene responsible for intramuscular fat content in musculus longissimus muscle [7] [8]. These findings suggested that PNLIP was a positional and functional candidate for the marbling gene. We recently showed that a single nucleotide polymorphism (SNP) referred to as rs41648172 in intron 6 region of the PNLIP was associated with marbling in Japanese Black beef cattle [9].

It has been reported that a causal mutation responsible for a variation of quantitative traits is often located in the promoter region affecting gene expression [10]-[14]. In this study, we thus explored a novel PNLIP promoter SNP associated with marbling in Japanese Black beef cattle. We first found a SNP in the promoter region of PNLIP between Holstein steers and somatic nuclear-derived cloned steers from a Japanese Black sire with a very high estimated breeding value for marbling by sequencing analysis. Furthermore, we examined allelic distributions in the SNP between high-marbled and low-marbled Japanese Black beef cattle. The polymorphism in the promoter region of PNLIP might be associated with marbling by altering its gene expression, and be useful for effective marker-assisted selection to increase the levels of marbling.

\section{Materials and Methods}

\subsection{Samples and Data}

Two Holstein steers and 2 somatic nuclear-derived cloned steers [15] from a Japanese Black Itofuku sire with a very high estimated breeding value for marbling [16] were used for polymorphism detection. We used 2 highmarbled cloned steers to confirm the authenticity of a SNP detected in the promoter region of PNLIP.

Further, we used 34 Japanese Black unrelated sires (17 sires with extremely high predicted breeding values for marbling and 17 sires with extremely low ones) selected from 101 unrelated sires, a panel of which represent almost all of the lines within a Japanese Black beef cattle population, for SNP genotyping in this study. The predicted breeding values of the sires for beef marbling standard number were obtained from the Oita recording system for beef cattle previously reported by Sasaki et al. [17]. The accuracy of the predicted breeding values in the 101 sires was $0.935 \pm 0.008$, ranging from 0.770 to 0.990 . Semen or blood were collected from the steers and sires, and DNA samples were prepared from the materials according to standard protocols. This study conformed to the guidelines for animal experimentation of the Graduate School of Science and Technology, Niigata University (Niigata, Japan).

\subsection{Polymorphism Detection}

We screened the NCBI databases (National Center for Biotechnology Information, Bethesda, MD), and obtained the bovine genomic sequence (AC_000183.1) containing PNLIP. PCR primers were designed to target $\sim 3.5-\mathrm{kb}$ 5' flanking region of $P N L I P$, in order to screen polymorphisms in the gene between 2 low-marbled Holstein steers and 2 high-marbled cloned steers. Primer pairs used for amplifications of that region were as follows: GAATCAGAGCCGAAACATATTAAA (g.37286903-37286926) and TCACGTCCATTGAGTTGGTG (g.37288830-37288811), CACCTGATGCAAAGAGCTGA (g.37288707-37288726) and CTACGACTGCTCCCAGCAAC (g.37290564-37290545). PCR amplifications were performed using $25 \mathrm{ng}$ of the prepared DNA as tem- 
plate in a final volume of $100 \mu$ containing $0.5 \mu \mathrm{M}$ of each primer, $0.2 \mathrm{mM}$ of each dNTP, $0.625 \mathrm{U}$ of Ex Taq polymerase (Takara, Shiga, Japan), and $1 \mathrm{X}$ Ex Taq buffer (Takara). The PCR condition was as follows: $94^{\circ} \mathrm{C}$ for $3 \mathrm{~min}, 35$ cycles of $94^{\circ} \mathrm{C}$ for $50 \mathrm{~s}, 60^{\circ} \mathrm{C}$ for $50 \mathrm{~s}$, and $72^{\circ} \mathrm{C}$ for $90 \mathrm{~s}$, followed by a further 5 -min extension at $72^{\circ} \mathrm{C}$. PCR products were examined by electrophoresis through a $1.0 \%$ agarose gel to determine the quality and quantity for DNA sequencing. DNA sequencing of PCR-amplified products was performed using DNA sequencing service provided by SolGent Co, Ltd (Daejeon, South Korea). Nucleotide polymorphisms were identified by comparison of sequence traces among the 4 DNA samples, and designated according to nomenclature for the description of sequence variations in the HGVS (Human Genome Variation Society, Fitzroy, VIC, Australia).

\subsection{SNP Genotyping}

A SNP detected in the promoter region of PNLIP, g.37288470A $>\mathrm{G}$, was genotyped by the PCR-restriction fragment length polymorphism method as described previously [18]. PCR primers used for amplifications of 399-bp region containing the SNP site were CAAAGATCACCTAAATTATGGATTAAA (g.37288421-37288447) and GAGTTGGTGATGCCATCTGA (g.37288819-37288800). PCR amplifications were carried out as described in Polymorphism Detection section, using a final volume of $20 \mu$. The PCR condition was as follows: $94^{\circ} \mathrm{C}$ for $3 \mathrm{~min}, 35$ cycles of $94^{\circ} \mathrm{C}$ for $50 \mathrm{~s}, 60^{\circ} \mathrm{C}$ for $50 \mathrm{~s}$, and $72^{\circ} \mathrm{C}$ for $50 \mathrm{~s}$, followed by a further 5 -min extension at $72^{\circ} \mathrm{C}$. An aliquot of PCR-amplified product was digested at $37^{\circ} \mathrm{C}$ for $1 \mathrm{~h}$ with restriction enzyme DdeI and electrophoresed on a 3.5\% agarose gel. Agarose gels were stained with ethidium bromide and photographed under an ultraviolet light. 399-bp PCR fragments containing the SNP site were digested into 47-, 79- and 273-bp fragments at the $A$ allele, but into 126- and 273-bp fragments at the $G$ allele: the $A A$ homozygotes, the $G G$ homozygotes and the $A G$ heterozygotes yielded 3 bands (47, 79, and $273 \mathrm{bp}$ ), 2 bands (126 and $273 \mathrm{bp}$ ) and 4 bands $(47,79,126$, and $273 \mathrm{bp})$, respectively (Figure 1).

\subsection{Statistical Analyses}

The allelic distributions in the g.37288470A > G SNP were compared between 17 sires with extremely high predicted breeding values for marbling and 17 sires with extremely low ones, by chi-square test. Statistical analysis was performed by the FREQ procedure of SAS program (SAS Institute, Inc, Cary, NC).

\section{Results and Discussion}

The sequence analysis revealed a SNP in the promoter region of PNLIP from 2 low-marbled Holstein steers and 2 high-marbled cloned steers: an $A$ to $G$ transition located at 1917 bp upstream of the transcription initiation site (g.37288470A > G). This SNP corresponded to rs381061632 reported previously [19]. The 2 low-marbled Holstein steers were homozygous for $A$ allele at the g.37288470A $>\mathrm{G}$ site, whereas the 2 high-marbled cloned steers were heterozygous for $A$ and $G$ alleles.

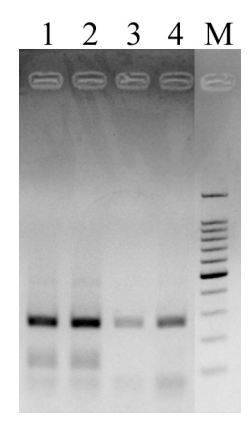

Figure 1. SNP genotyping of g.37288470A > G. Lanes 1 and 2 show electrophoretic pattern of $D d e$ I-digested PCR products from $A G$ heterozygotes (from top to bottom, 273, 126 and 79 $\mathrm{bp}$ ). Lanes 3 and 4 show electrophoretic pattern of DdeI-digested PCR products from $A A$ homozygotes (from top to bottom, 273 and $79 \mathrm{bp}$ ). Lane M shows DNA size marker (from top to bottom, 1500, 1000, 900, 800, 700, $600500,400,300,200$ and $100 \mathrm{bp}$ ). 
Table 1. Comparison of allelic distributions in the g.37288470A $>$ G SNP between 17 sires with extremely high predicted breeding values for marbling and 17 sires with extremely low ones.

\begin{tabular}{|c|c|c|c|c|}
\hline \multirow{2}{*}{ Sires } & \multicolumn{2}{|c|}{ Table Column Head } & \multirow{2}{*}{$x^{2}$ value } & \multirow{2}{*}{$P$ value } \\
\hline & $A$ allele & $G$ allele & & \\
\hline $\begin{array}{l}\text { With high } \\
\text { breeding value }\end{array}$ & 0.588 & 0.412 & \multirow{2}{*}{4.5333} & \multirow{2}{*}{0.0332} \\
\hline $\begin{array}{c}\text { With low } \\
\text { breeding value }\end{array}$ & 0.824 & 0.176 & & \\
\hline
\end{tabular}

We genotyped 34 Japanese Black unrelated sires consisting of 17 sires with extremely high predicted breeding values for marbling and 17 sires with extremely low ones, for the g.37288470A > G SNP, and found statistically significant difference in the allelic distribution between 17 sires with extremely high breeding values and 17 sires with extremely low ones $(\mathrm{P}=0.0332)$ (Table 1$)$. The $G$ allele at the g.37288470A $>\mathrm{G}$ was more frequent in animals with the high breeding values than with the low ones, and the $A$ allele in animals with the low ones than with the high ones (Table 1).

In the previous study, we supposed that PNLIP was responsible for the intramuscular fat content in the rat [7] [8]. This study, together with the mapping of a marbling quantitative trait locus within genomic region containing PNLIP on bovine chromosome 26 [6], and the association of rs41648172 SNP in intron 6 region with marbling [9], suggests that PNLIP SNPs are associated with bovine marbling. It may be true that the g. 37288470A > GSNP in the promoter region of $P N L I P$ is functional and directly affect marbling by altering its gene expression, because a causal mutation responsible for a variation of quantitative traits such as marbling is reported to be often located in the promoter region affecting gene expression [20]. However, a more likely event is that the SNP is in linkage disequilibrium with an unidentified true causal mutation. Thus, further replication and biochemical studies will be needed to confirm the g.37288470A $>$ G SNP as the causal mutation for marbling.

Irrespective of the confirmation of the g.37288470A $>$ G SNP as the causal mutation, these findings suggest that the g.37288470A $>$ G SNP of PNLIP is a useful marker for effective marker-assisted selection to increase the levels of marbling in Japanese Black beef cattle. We have recently reported that SNPs in the endothelial differentiation sphingolipid G-protein-coupled receptor 1 (EDG1) [11], titin (TTN) [12], akirin 2 (AKIRIN2) [13], and ribosomal protein L27a (RPL27A) genes [14] were associated with marbling in Japanese Black breed. Thus, the present study seems to be an additional report to show polymorphisms associated with marbling using Japanese Black breed.

\section{Conclusion}

In this study, we showed that g.37288470A > G SNP in the promoter region of PNLIP might be associated with marbling in Japanese Black beef cattle. This study will provide useful information for the establishment of effective marker-assisted selection to increase the levels of marbling in Japanese Black beef cattle.

\section{Acknowledgements}

This work was supported by a Grant-in-Aid for Scientific Research (B) (No. 14360166) from the Ministry of Education, Culture, Sports, Science and Technology of Japan, and by the research funds of Japanese Livestock Technology Association.

\section{References}

[1] Boylston, T.D., Morgan, S.A., Johnson, K.A., Busboom, J.R., Wright Jr., R.W. and Reeves, J.J. (1995) Lipid Content and Composition of Wagyu and Domestic Breeds of Beef. Journal of Agricultural and Food Chemistry, 43, 12021207. http://dx.doi.org/10.1021/jf00053a015

[2] Busboom, J.R., Jeremiah, L.E., Gibson, L.L., Johnson, K.A., Gaskins, C.T., Reeves, J.J. and Wright Jr., R.W. (1993) Effects of Biological Source on Cooking and Palatability Attributes of Beef Produced for the Japanese Market. Meat Science, 35, 241-258. http://dx.doi.org/10.1016/0309-1740(93)90054-L

[3] Matsuishi, M., Fujimori, M. and Okitani, A. (2001) Wagyu Beef Aroma in Wagyu (Japanese Black Cattle) Beef Preferred by the Japanese over Imported Beef. Animal Science Journal, 72, 498-504. http://dx.doi.org/10.2508/chikusan.72.498 
[4] Japan Meat Grading Association (1988) New Beef Carcass Grading Standards. Japan Meat Grading Association, Tokyo.

[5] Lowe, M.E. (2002) The Triglyceride Lipases of the Pancreas. Journal of Lipid Research, 43, 2007-2016. http://dx.doi.org/10.1194/jlr.R200012-JLR200

[6] Takasuga, A., Watanabe, T., Mizoguchi, Y., Hirano, T., Ihara, N., Takano, A., Yokouchi, K., Fujinaka, A., Chiba, K., Kobayashi, N., Tatsuda, K., Oe, T., Furukawa-Kuroiwa, M., Nishimura-Abe, A., Fujita, T., Inoue, K., Mizoshita, K., Ogino, A. and Sugimoto, Y. (2007) Identification of Bovine QTL for Growth and Carcass Traits in Japanese Black Cattle by Replication and Identical-by-Descent Mapping. Mammalian Genome, 18, 125-136. http://dx.doi.org/10.1007/s00335-006-0096-5

[7] Tanomura, H., Taniguchi, Y., Muramatsu, Y., Kose, H., Miyake, T., Matsumoto, K., Yamada, T. and Sasaki, Y. (2003) A Congenic Strain (F344.OLETF-Imfm) Displays the Existence of Intramuscular Fat Accumulation QTL on Rat Chromosome 1. Experimental Animals, 52, 303-308. http://dx.doi.org/10.1538/expanim.52.303

[8] Muramatsu, Y., Yamada, T., Taniguchi, Y., Ogino, T., Kose, H., Matsumoto, K. and Sasaki, Y. (2007-2008) PNLIP Encoding Pancreatic Lipase Is a Possible Candidate for Intramuscular Fat Accumulation QTL in OLETF Rat. Research Communications in Molecular Pathology and Pharmacology, 120-121, 23-32.

[9] Tanomura, H., Yamamoto, T., Muramatsu, Y., Ohta, T., Kose, H. and Yamada, T. (2011) The Pancreatic Lipase Gene Is Associated with Marbling in Japanese Black Beef Cattle. Journal of Animal and Veterinary Advances, 10, 17191723. http://dx.doi.org/10.3923/javaa.2011.1719.1723

[10] Yamada, T., Itoh, M., Nishimura, S., Taniguchi, Y., Miyake, T., Sasaki, S., Yoshioka, S., Fujita, T., Shiga, K., Morita, M. and Sasaki, Y. (2009) Association of Single Nucleotide Polymorphisms in the Endothelial Differentiation Sphingolipid G-Protein-Coupled Receptor 1 Gene with Marbling in Japanese Black Beef Cattle. Animal Genetics, 40, 209-216. http://dx.doi.org/10.1111/j.1365-2052.2008.01822.x

[11] Yamada, T., Sasaki, S., Sukegawa, S., Miyake, T., Fujita, T., Kose, H., Morita, M., Takahagi, Y., Murakami, H., Morimatsu, F. and Sasaki, Y. (2009) Novel SNP in 5' Flanking Region of EDG1 Associated with Marbling in Japanese Black Beef Cattle. Animal Science Journal, 80, 486-489. http://dx.doi.org/10.1111/j.1740-0929.2009.00665.x

[12] Yamada, T., Sasaki, S., Sukegawa, S., Yoshida, S., Takahagi, Y., Morita, M., Murakami, H., Morimatsu, F., Fujita, T., Miyake, T. and Sasaki, Y. (2009) Association of a Single Nucleotide Polymorphism in Titin Gene with Marbling in Japanese Black Beef Cattle. BMC Research Notes, 2, 78. http://dx.doi.org/10.1186/1756-0500-2-78

[13] Sasaki, S., Yamada, T., Sukegawa, S., Miyake, T., Fujita, T., Morita, M., Ohta, T., Takahagi, Y., Murakami, H., Morimatsu, F. and Sasaki, Y. (2009) Association of a Single Nucleotide Polymorphism in Akirin 2 Gene with Marbling in Japanese Black Beef Cattle. BMC Research Notes, 2, 131. http://dx.doi.org/10.1186/1756-0500-2-131

[14] Yamada, T., Sasaki, S., Sukegawa, S., Miyake, T., Fujita, T., Kose, H., Morita, M., Takahagi, Y., Murakami, H., Morimatsu, F. and Sasaki, Y. (2009) Association of a Single Nucleotide Polymorphism in Ribosomal Protein L27a Gene with Marbling in Japanese Black Beef Cattle. Animal Science Journal, 80, 631-635. http://dx.doi.org/10.1111/j.1740-0929.2009.00688.x

[15] Shiga, K., Fujita, T., Hirose, K., Sasae, Y. and Nagai, T. (1999) Production of Calves by Transfer of Nuclei from Cultured Somatic Cells Obtained from Japanese Black Bulls. Theriogenology, 52, 527-535. http://dx.doi.org/10.1016/S0093-691X(99)00149-1

[16] Oita Prefectural Institute of Animal Industry (1999) Sire Summary. Oita Prefectural Institute of Animal Industry, Oita.

[17] Sasaki, Y., Miyake, T., Gaillard, C., Oguni, T., Matsumoto, M., Ito, M., Kurahara, T., Sasae, Y., Fujinaka, K., Ohtagaki, S. and Dougo, T. (2006) Comparison of Genetic Gains per Year for Carcass Traits among Breeding Programs in the Japanese Brown and the Japanese Black Cattle. Journal of Animal Science, 84, 317-323.

[18] Tanomura, H., Yamamoto, T., Muramatsu, Y., Ohta, T., Kose, Y. and Yamada, T. (2011) Difference in PNLIP Allele Frequency Distribution between High-Marbled and Low-Marbled Cattle. Journal of Animal and Veterinary Advances, 10, 1714-1718. http://dx.doi.org/10.3923/javaa.2011.1714.1718

[19] http://www.ncbi.nlm.nih.gov/projects/SNP/snp_ref.cgi?rs=381061632

[20] Mackay, T.F. (2004) The Genetic Architecture of Quantitative Traits: Lessons from Drosophila. Current Opinion in Genetics \& Development, 14, 253-257. http://dx.doi.org/10.1016/j.gde.2004.04.003 